\title{
TERRITORIALIDADE E A GESTÃO PÚBLICA DOS AMBIENTES NATURAIS DO RIO DE JANEIRO
}

\author{
TERRITORIALITY AND PUBLIC MANAGEMENT OF NATURAL ENVIRONMENTS IN RIO DE JANEIRO
}

\author{
Saulo Cezar Guimarães de Farias \\ Universidade do Estado do Rio de Janeiro (UERJ), Rio de Janeiro, RJ, Brasil, saulocg@bol.com.br \\ Elza Maria Neffa Vieira de Castro \\ Universidade do Estado do Rio de Janeiro (UERJ), Rio de Janeiro, RJ, Brasil, elzaneffa@gmail.com \\ Mario Luiz Gomes Soares \\ Universidade do Estado do Rio de Janeiro (UERJ), Rio de Janeiro, RJ, Brasil, mariolgs@gmail.com
}

\begin{abstract}
RESUMO
O povo brasileiro se orgulha por ter uma legislação ambiental considerada das mais completas e modernas do planeta. Entretanto, o orgulho se transforma em decepção quando indivíduos e organizações subvertem os dispositivos legais para alcançar seus objetivos sem se preocupar com o dano ambiental e com os conflitos sociais que suas ações potencializam. O presente trabalho usa como estratégias metodológicas uma revisão bibliográfica sobre publicações que discutem a construção dos dois empreendimentos, um levantamento histórico sobre o crescimento da região metropolitana do estado do Rio de Janeiro e uma crítica pautada no conceito de territorialidade e de conflitos e vulnerabilidades socioambientais das ciências ambientais de modo a constatar as manipulações jurídicas, flexibilizações e arranjos na legislação ambiental para que os empreendimentos sejam construídos. Evidenciou que os interesses públicos e privados conseguem se sobrepor a qualquer dispositivo legal que se coloca como impedimento destas ações, que o discurso reducionista minimiza as críticas e os conflitos socioambientais são recorrentes nestas situações.
\end{abstract}

Palavras-chave: Conflitos socioambientais; Políticas ambientais; Rio de Janeiro; Grandes projetos.

\begin{abstract}
The Brazilian people are proud to have an environmental law considered the most complete and modern planet. However, pride turns to disappointment when individuals and organizations subvert the legal mechanisms to achieve their goals without worrying about the environmental damage and social conflicts that potentiate their actions. This paper uses as methodological strategies a literature review of publications that discuss the construction of the two projects, a historical survey of the growth of the metropolitan region of the state of Rio de Janeiro and a guided critique the concept of territoriality and conflict and environmental vulnerabilities environmental sciences in order to observe the legal manipulations, flexibilities and arrangements in environmental legislation to which the projects are built. Showed that public and private interests can overwhelm any legal provision that arises as preventing these actions, the reductionist discourse minimizes the criticism and environmental conflicts are recurrent in these situations.
\end{abstract}

Keywords: Environmental conflicts; Environmental policies; Rio de Janeiro; Great designs.

Artigo recebido para publicação em março de 2014

Artigo aceito para publicação em fevereiro de 2015

\section{INTRODUÇÃO}

O território do município do Rio de Janeiro tem sido cenário de disputa de grupos com os mais variados tipos de interesses. A intensificação dos conflitos pela apropriação/uso desta região ocorrida nas últimas três décadas, tem influenciado a dinâmica socioespacial da segunda maior metrópole brasileira. Os arranjos, entendidos também aqui como acordos, implementação de projetos e reorganização 
territorial, pretendeu atender às demandas econômicas do país e das três esferas de governo que tinham a região como "gargalo logístico" das atividades extrativistas e como foco do interesse turístico nacional e internacional.

Como parâmetros para o entendimento dos fenômenos potenciadores e geradores das distorções jurídicas, dos arranjos políticos e dos conflitos socioambientais que emergiram no estado do Rio de Janeiro nos últimos anos, foram selecionados dois casos que se julgou representarem os interesses estratégicos do governo federal e grandes motivadores para a valorização do território, sendo alvo de uma gama de situações controversas evolvendo a utilização de áreas legalmente protegidas.

Os casos que subsidiarão a análise se remetem a duas áreas naturais preservadas do estado onde se acreditava estarem protegidas contra qualquer ameaça de exploração, a Área de Proteção Ambiental (APA) de Marependi e a região onde está sendo construído o Complexo Petroquímico do Rio de Janeiro (COMPERJ), no município de Itaboraí.

Para que a problemática seja evidenciada será utilizada como estratégias metodológicas uma revisão e análise bibliográfica sobre publicações que discutem a construção dos dois empreendimentos, um levantamento histórico sobre o crescimento da região metropolitana do estado do Rio de Janeiro e uma crítica pautada no conceito de territorialidade e de conflitos e vulnerabilidades socioambientais das ciências ambientais, articuladando os interesses públicos e privados com a questão ambiental apontando os principais entraves para a consolidação da legislação ambiental no município, sendo um tema recente e que adquiriu grande importância num curto espaço de tempo.

Partindo de pressupostos que evidenciam a lógica do desenvolvimento sociometabólico capitalista como "fio condutor" e "legitimador" de manipulações e ações ilegais para transformação das áreas legalmente protegidas em nome do progresso e da acumulação da riqueza abstrata. 
O estudo dessa dinâmica serve para o entendimento destes conflitos socioambientais do estado do Rio de Janeiro e em diversos espaços suscetíveis à interesses diversos e será um valioso subsídio para quem se debruça na análise das questões socioambientais.

\section{O desenvolvimentismo brasileiro da década de 1970 e o embate ecológico}

Desde a apropriação do pensamento baconiano em que o homem se torna o senhor da natureza, e não mais parte do natural, a relação desequilibrada entre homem-meio ambiente se acentuou. Diante do atual modelo de desenvolvimento econômico propagado como visão hegemônica, que tem orientado o processo de modernização do Brasil e, de forma mais acentuada do estado do Rio de Janeiro, passaram a emergir conflitos socioambientais emergiram quando houve adequação do meio ambiente e da sociedade à interesses particulares.

Santos (1994) afirma que a história do ser humano sobre a Terra é "a história de uma rotura progressiva entre homem e o entorno". Se a técnica permitiu à humanidade tomar a natureza artificial, esse processo correspondeu a vários períodos dos estágios de evolução humana, o que significa dizer, que mesmo as comunidades primitivas intervinham de alguma maneira sobre o meio e seus recursos com as técnicas que, naquele momento, lhes permitiam efetivar tal intervenção. Mas quando a "ciência e a técnica se associaram, resultando em sucessivas descobertas tecnológicas e a economia se tornou mundializada, todas as sociedades adotaram um mesmo modelo que se sobrepõe aos múltiplos recursos naturais e humanos" (CARRIL, 2002 p. 4).

Existe um consenso na ideia que grande parte dos projetos para o desenvolvimento do país ocorreram e ocorrem com pouco planejamento e de forma equivocada, principalmente quando estão atreladas às questões ambientais (FOLADORI, 2001; LAYRARGUES, 2002; LOUREIRO, 2004).

Conforme o país assumia seu papel na divisão internacional do trabalho (DIT) fornecendo ao mundo alimentos e energia, seus ambientes naturais eram menosprezados e as leis pouco eficazes para proteger o que ainda permanecia intocado (ACSERALD, 2012; ZHOURI, 2005) não servindo ao 
menos para criar um parâmetro entre o certo e o errado, quando se pretendia usufruir de algum recurso natural.

As legislações das décadas de 1930 e 1960 tinham um caráter desenvolvimentista que perdurou durante décadas, incentivando a exploração do meio ambiente visando apenas os estabelecimentos das cidades provocando lesões ambientais. As esparsas e ineficientes leis que foram surgiram ao longo dessa época se fizeram no sentido de buscar regrar a utilização dos bens naturais (DÓREA, 2012).

Segundo Santos (1994, p. 97):

\footnotetext{
É nessas condições que a mundialização do planeta unifica a natureza. Suas diversas frações são postas ao alcance dos mais diversos capitais, que as individualizam, hierarquizando-as segundo lógicas com escalas diversas. A uma escala mundial corresponde uma lógica mundial que nesse nível guia os investimentos, a circulação das riquezas, a distribuição das mercadorias. Cada lugar, porém, é ponto de encontro de lógicas que trabalham em diferentes escalas, reveladoras de níveis diversos, e às vezes contrastantes, na busca da eficácia e do lucro, no uso das tecnologias do capital e do trabalho.
}

A distribuição das competências de fiscalização e monitoramento da atividade industrial no Brasil teve uma nova dinâmica no final do século XX. O ímpeto desenvolvimentista das décadas de 1950, 1960 e 1970, sem grandes preocupações com danos ambientais, subverteu toda a organização das instituições responsáveis pela gestão ambiental no país.

O país travava uma luta ideológica na qual a necessidade de progresso estaria sempre à frente das decisões políticas e no escopo das discussões internas, mesmo que as deliberações vindas das conferências internacionais de meio ambiente apontassem que os países deveriam implantar os projetos para proteger, resguardar e restaurar os seus ambientes naturais (LAYRARGUES, 2002; LOUREIRO, 2004).

No Brasil, a inserção tardia no processo de industrialização teve reflexos em outras áreas. Os sucessivos períodos desenvolvimentistas ignoraram uma gama de questões socioambientais que não poderiam atravancar o progresso do país e permaneceram em segundo plano por décadas. 
O grande salto entre governos monopolistas de estado para o neoliberalismo com ausência do estado de bem estar social, foi o responsável pelos inúmeros problemas sociais e econômicos que acometem a população.

Na década seguinte (1980), com a criação da Política Nacional de Meio Ambiente (PNMA, 1981), as questões ambientais tiveram nova importância no escopo das agendas das três esferas de governo do país, sendo a mesma reforçada pela Constituição de 1988.

A PNMA foi instituída para trabalhar conjuntamente e coordenadamente com o Sistema Nacional de Meio Ambiente (SISNAMA) e o Conselho Nacional de Meio Ambiente (CONAMA), instrumentos de gestão e regulamentação, onde o CONAMA atua através do acesso da opinião pública às informações relativas às agressões ao meio ambiente e às ações de proteção ambiental, e o SISNAMA, composto de órgãos e instituições de diversos níveis do Poder Público, elabora normas e padrões supletivos e complementares.

Ainda neste período, foi atribuído ao país o papel de articulador internacional da luta pela preservação ambiental, sendo sede de uma das mais importantes convenções internacionais sobre o meio ambiente, a Conferência das Nações Unidas sobre o Meio Ambiente e o Desenvolvimento (Rio 92) ou Cúpula da Terra. Nesta Conferência foram ampliados os debates e as discussões sobre o desenvolvimento sustentável, que tinham sido iniciadas em 1972, na Conferência de Estocolmo, da qual resultou a Declaração de Estocolmo.

A Rio 92 consolidou uma agenda global para o meio ambiente e favoreceu a descentralização das obrigações da gestão dos recursos e ambientes naturais dos países, com os diversos setores da sociedade civil e política.

Neste quadro que estava sendo criado, onde intrínsecas relações sociais, políticas, econômicas e ambientais se formavam, as políticas públicas precisariam atender às necessidades da dinâmica da acumulação do capital e do projeto neoliberal qual o país aderira. 0 que se esperava, entretanto, era 
que as políticas ambientais brasileiras passassem a ser construídas com o objetivo de minimizar e mitigar os problemas gerados por conflitos e interesses do "grande capital", o que, de fato, não ocorreu.

Carril (2002 p. 2) enfatiza que o paradigma ambiental parece estar centrado em países "onde os problemas sociais não são tão prementes, como no caso das sociedades dos países do Primeiro Mundo e onde os impactos ambientais são maiores devido à formação de sociedades de consumo". A questão está relacionada às desiguais formações sócio-econômicas no mundo globalizado, às diferentes formas de constituição das sociedades civis na questão da desigualdade, da democracia e dos embates políticos quanto à questão da propriedade, da democracia e do Estado (CARRIL, 2002).

\section{Território e territorialidade e o Rio de Janeiro em destaque}

A análise da dinâmica territorial no Brasil é objeto de pesquisa de geógrafos (SANTOS, 1992; HAESBAERT, 2006) que se dedicam a estudar a construção do espaço e do comportamento dos fenômenos que ocorrem nas relações entre os seres humanos e o meio.

No estado do Rio de Janeiro existem particularidades que representam o universo de acontecimentos que são característicos as metrópoles do centro-sul do país, uma história de crescimento pautada na produção agrícola, na explosão demográfica das cidades litorâneas e na ocorrência de diversos conflitos socioambientais como consequência dessa desorganização.

Segundo Franca et al. (2012, p. 117) o estudo da construção territorial do estado é necessário [...] "na medida em que se pretende compreender de que forma são construídos ambientes intangíveis que fazem materializar e consolidam (ou não) as políticas, comportamentos e relacionamentos, sejam eles quais forem, conferindo-lhes características próprias e indissociáveis”.

Ainda segundo o autor (p. 119) "é impossível tratar de qualquer dimensão de território e de territorialidade, sem que se passe pela concepção de território físico, do espaço físico onde se produz 
todos os outros tipos de territorialidades derivadas da concepção humana [...] "dessa forma, a construção de qualquer tipo de territorialidade à mais fundamental delas, que é a territorialidade física da terra, como espaço natural”.

O estado do Rio de Janeiro possui grande influencia no cenário Federal como região onde são travados intensos embates entre as forças econômica, política e ambiental. A grande variedade de biomas, que disputa espaço com uma expansão urbana acelerada gerada pelo crescimento populacional e pela atividade petrolífera, fez com que o estado estivesse no centro de grandes interesses, tanto de ambientalistas e pesquisadores quanto políticos e grandes corporações, nacionais e internacionais, que querem explorar os hidrocarbonetos da região.

Estes fatos proporcionaram uma valorização estratégica do território, subsidiaram a especulação imobiliária e, consequentemente, aumentaram a periferização, a favelização (RIBEIRO, 1977) e a pressão sobre os ambientes naturais e os ecossistemas presentes na região metropolitana do estado (Figura 1).

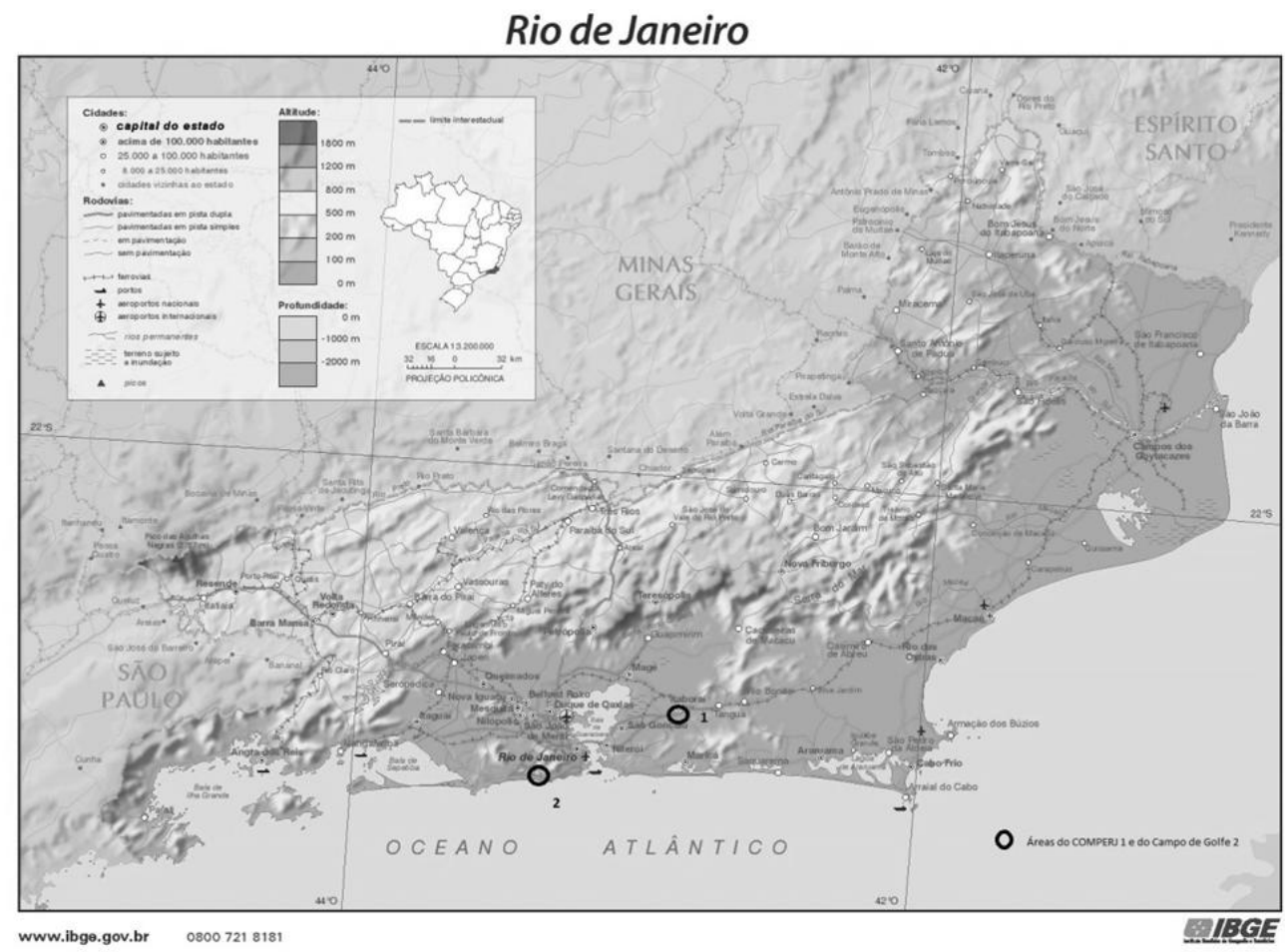

Figura 1. Mapa físico do Estado do Rio de Janeiro e áreas de estudo Fonte: Adaptado de :

ftp://geoftp.ibge.gov.br/mapas_tematicos/mapas_escolares/ensino_medio/mapas_estaduais/pdf/rio_de_janeiro.pdf. 
A gestão do território, como Corrêa (1996) apresenta como sendo a dimensão espacial do processo de controle do Estado, grupo social, instituição ou empresa, é o articulador para a compreensão dos fenômenos que se refletiram no processo de urbanização das metrópoles brasileiras e nos seus ambientes naturais nos últimos 50 anos.

O estado de reestruturação que o município sofreu e está sofrendo também é reflexo da atual conjuntura político-econômica que o governo decidiu adotar e responsável pelo surgimento de uma maior infraestrutura urbana atendendo aos interesses privados e trazendo melhorias substanciais no cotidiano da população do município.

O ápice da deflagração dos embates políticos que ocorriam no país, em detrimento das necessidades capitalistas-hegemônicas (FOLADORI, 2001; ACSERALD, 2002; CHESNAIS, 2003) também observado nas transformações econômicas sofridas no início do século XXI, e na escolha do Brasil para sediar grandes eventos internacionais como a Copa do Mundo de Futebol e as Olimpíadas.

Para atendimento das pseudos necessidades do Estado diante da sua escolha como sede dos eventos, empreendeu-se um conjunto de obras de infraestrutura e de adequação dos estabelecimentos esportivos as determinações das instituições responsáveis pela organização das atividades esportivas. Muitas destas obras foram estabelecidas em áreas públicas de posicionamento estratégico, mas que, em muitos casos, continham biomas preservados por Leis Federais. Os embates que antes estavam nos bastidores emergiram e intensas batalhas travadas nos espaços políticos e jurídicos para o a utilização de áreas naturais preservadas passaram a fazer parte dos noticiários jornalísticos do país (VELHO, 1989).

Abreu (1997, p. 34) comenta que, além disso, essa realidade repercute com mais intensidade diante da “importância da cidade no contexto nacional, não só pela sua história como pela grande diversidade de ambientes naturais existentes no seu espaço urbano". 
As considerações expostas até aqui são semelhantes à observação do autor (p. 34) que afirma que "a forma como evoluiu a cidade a partir da virada do século XIX se deu a partir das preocupações em transformá-la numa cidade comparável às grandes capitais mundiais e/ou como espaço privilegiado de ação de setores privados do capital". "No bojo dessas mudanças não foram medidos esforços para que os projetos fossem realizados, mesmo que isso significasse a destruição dos patrimônios histórico e natural" (ABREU, 1997, p. 34).

\section{O COMPERJ}

A criação do COMPERJ é reflexo do momento histórico que o país vive com grandes investimentos em projetos de infraestrutura, sendo a indústria petrolífera a "chave mestra" para alavancar a economia dos estados litorâneos e servir de base para outros demais projetos energéticos (CASTRO et al., 2003).

O COMPERJ exemplifica um setor que, anualmente, movimenta no mundo algo em torno de cinco trilhões de dólares (ALÉM et al., 2010). A importância estratégica da sua construção como fonte de inúmeros recursos financeiros para os entes federados, revela o quão disposto está o Governo Federal para mitigar os entraves jurídicos e sociais e subjugar a legislação ambiental para que o empreendimento seja realizado.

A abundância de procedimentos legais para que o complexo petroquímico fosse construído já estavam contabilizados e previamente encaminhados pelas instâncias político-jurídicas e não se tornariam empecilhos para o prosseguimento das obras, porém, o licenciamento ambiental se tornaria o maior entrave para que o empreendimento pudesse ser iniciado e terminado no tempo previsto.

É através do licenciamento que o Estado (por intermédio dos órgãos técnicos de meio ambiente) avalia as consequências positivas e negativas de um empreendimento e, em tese, determina sua autorização ou não considerando sua viabilidade ambiental (FAUSTINO \& FURTADO, 2013). No caso de projetos causadores de significativa degradação ambiental é exigido o Estudo de Impacto Ambiental 
(EIA), conforme previsão do art. 225, parágrafo 10 inciso IV da Constituição de 1988 (BRASIL, 1988).

Durante o processo, o Poder Público expedirá: a Licença Prévia (LP), concedida na fase de planejamento do projeto, a Licença de Instalação (LI), que autoriza a instalação do empreendimento, e a Licença de Operação (LO), que autoriza a operação do empreendimento. A Resolução do CONAMA também determina a competência dos órgãos federais, estaduais e municipais em torno do licenciamento (BRASIL, 1997).

Faustino \& Furtado (2013) esclarecem que conforme explicita a Lei Estadual no 3.111, de 18 de novembro de 1998, o processo de licenciamento ambiental de um empreendimento em uma bacia hidrográfica, onde já existem outros projetos, haveria necessidade de ter, como fundamento, uma análise conjunta e estrutural de todos os empreendimentos. Uma análise integrada dos empreendimentos permitiria a avaliação aprofundada das condições dos ecossistemas da região e da dinâmica socioeconômica local já impactada por outros projetos (FAUSTINO \& FURTADO, 2013).

Realmente as várias irregularidades encontradas pelo Ministério Público (MP) para na concessão do licenciamento (concedidas pelo Instituto Estadual do Ambiente - INEA) paralizaram as obras. Porém, as decisões foram cassadas e as obras continuaram a serem executadas. Em determinada ação:

\footnotetext{
...o juiz federal substituto da $2^{\text {a }}$ Vara Federal de Itaboraí, Eduardo Ribeiro Filho, suspendeu as obras atendendo a uma ação do Ministério Público Federal (MPF), de 2008, que apontava irregularidades na concessão das licenças ambientais para a construção do complexo, que é vizinho à uma área de proteção ambiental. O MPF alega que a autorização do Inea não é suficiente para avaliar os impactos e os danos causados na região. Na decisão, o juiz determinou que é preciso autorização do Instituto Brasileiro do Meio Ambiente e Recursos Naturais Renováveis (IBAMA) (PIMENTEL, 2013).
}

Neste contexto, formulam-se inúmeras indagações acerca do verdadeiro objetivo do licenciamento ambiental [...] "e a vontade política dos governos na implantação de alguns empreendimentos que acelera e desburocratiza o processo de forma leviana, uma vez que ignora impactos gravíssimos no ecossistema e na vida da população local" (CAVALCANTI, 2010 p. 14). 
A particularidade desse empreendimento está no fato dele estar sendo realizado em um momento em que o Rio de Janeiro se consolida com uma unidade federativa de horizontalidade petrolífera (no que diz respeito à atividade e a sua cadeia produtiva, já que o estado agrega as suas diversas fases: a de extração, do refino e da produção de bens de consumo), gerando necessidades urbanísticas e enclaves políticos para as administrações públicas que passam a agir em conjunto e em rede.

Referente à construção do COMPERJ (Figura 2) o governo federal escolheu o município de Itaboraí RJ por estar também em uma posição estratégica, perto simultaneamente do município de Macaé - RJ onde se concentra praticamente toda a estrutura de produção do petróleo e também dos grandes centros de refino, distribuição e consumo do estado.

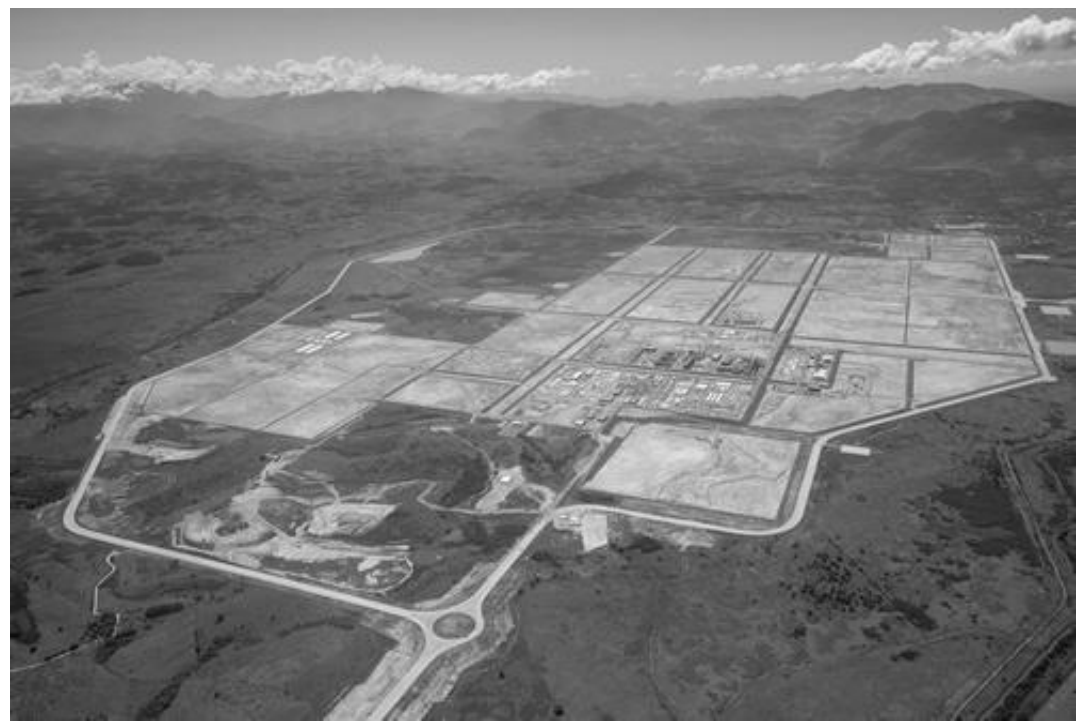

Figura 2. Área construída do COMPERJ

Fonte: Disponível em: http://www.comperj.com.br/Apresentacao.aspx Acesso em: 11 set. 2013.

Além da infração de muitos artigos do código florestal e da distorção de determinações dos órgãos responsáveis pela gestão ambiental do país, a construção deste empreendimento expõe problemas sociais intrínsecos, nas comunidades do seu entorno.

Cavalcanti (2010 p. 14) explica que o encaminhamento de "projetos de lei como o Projeto de Lei $n$ 388/2007, a edição de Medidas Provisórias como a 458 contida na Lei 11.952/09, e a 459 (que promove a regularização fundiária de assentamentos em áreas urbanas), igualmente convertida na Lei 
11977/09, são flagrantemente inconstitucionais em seu conteúdo" [...] "abrem caminho ao desmatamento e à ocupação de áreas de preservação ambiental, violando diretamente um dispositivo constitucional - artigo 225, bem como um direito fundamental que dele decorre e toda a lógica do direito do ambiente".

Reflexos diretos e indiretos destas ações afetam a população de maneiras diferentes, sendo de maior intensidade nas regiões e comunidades menos assistidas, mas também interferindo na qualidade de vida das classes sociais mais abastadas que se encontram nos limites das áreas naturais que estão sofrendo modificações.

Apesar da maior parte das áreas estarem em regiões periféricas ou afastadas dos centros urbanos, existem comunidades que vivem próximas às construções e estão vulneráveis aos efeitos nocivos da atividade, tanto dos movimentos de entrada e saída de matéria prima e insumos e uso direto da área, quanto os resíduos provocados pela produção.

De acordo com Faustino \& Furtado (2013) no Mapa da Justiça Ambiental do Estado do Rio de Janeiro (MJAERJ) elaborado pela Federação de Órgãos para Assistência Social e Educacional (FASE) e pelo Instituto de Pesquisa e Planejamento Urbano e Regional (IPPUR/UFRJ), encontramos informações que demonstram que determinadas localidades sofrem com práticas ambientalmente agressivas, atingindo populações de baixa renda.

$\mathrm{Na}$ área do empreendimento, moradores e moradoras são forçados a conviver com diversos problemas ambientais ao mesmo tempo: poluição industrial do ar e da água, depósitos de resíduos tóxicos, solos contaminados, ausência de abastecimento de água, baixos índices de arborização e riscos associados a enchentes, lixões e pedreiras (ACSELRAD, 2004).

Estes moradores residem nos municípios de Duque de Caxias, Magé e São Gonçalo, áreas de influência direta e indireta do COMPERJ, da REDUC e de outros empreendimentos do setor de petróleo, gás e petroquímica [...] "com maior número de população negra e de pescadores artesanais e com severas 
limitações de acesso à água, saneamento educação, saúde e emprego, as que são escolhidas como sede para a implantação de empreendimentos de alto impacto poluidor" (FAUSTINO \& FURTADO, 2013 p. 40).

Porém, devido ao uso dos territórios por atividades degradadoras que disputam o espaço e a biodiversidade com as populações que deles dependem, a pesca artesanal vem enfrentando sérios problemas para se manter como atividade econômica (FAUSTINO \& FURTADO, 2013). Esta situação é agravada pelos incentivos concedidos à pesca in-dustrial, pela negligência na fiscalização da sobrepesca e pela degradação dos ecossistemas que garantem a reprodução e qualidade dos ambientes e das espécies (ACSELRAD, 2004; FAUSTINO \& FURTADO, 2013 p. 40).

Nesta área e nas demais, os conflitos ambientais passaram a ocorrer quando existem desacordos no interior do arranjo espacial de atividades da localidade/região que passam a ocorrer continuamente com um tipo de ocupação do território, ameaçado pelo tipo de atividades, espacialmente conexas, que estavam sendo desenvolvidas (ACSERALD, 2005).

O estado do Rio de Janeiro ainda apresenta outro grande fator de atração de iniciativas e empreendimentos particulares e de infraestrutura, por ser um dos principais colégios eleitorais do governo petista e esse fato tem significância no direcionamento de verbas federais e na escolha do estado para tais ações.

Como ocorre em decisões de grande repercussão política, as irregularidades jurídicas e técnicas que marcaram seu processo de licenciamento estão fadadas a desaparecerem pelos inúmeros recursos e manipulações que o poder público impõe sobre o que é determinado legalmente (CAVALCANTI, 2010).

\section{A APA de Marapendi}


O segundo projeto, de cunho paisagístico e esportivo, prevê mudanças na Área de Proteção Ambiental (APA) de Marapendi na Barra da Tijuca para viabilizar a construção do Campo de Golfe Olímpico. 0 Parque de Marapendi seria ampliado no trecho conhecido como "reserva" enquanto que uma parte menor deixaria de ser protegida para ser incorporada à área do futuro campo de golfe.

Ryff (2002) comenta que antes de descrever, mesmo que parcialmente, o processo de ocupação da Barra da Tijuca sem mencionar a participação do Estado, seria ignorar a contribuição de um dos mais importantes agentes na produção do espaço da região juntamente com o capital incorporador.

Independentemente da análise na qual se julga se ele (o Estado) se constitui nesse processo como um agente neutro ou parcial, "é essencial destacar a importância da sua intervenção direta no espaço, que através da construção de túneis, elevados, estradas e provisão de infra-estrutura, tornou viável o acesso à região, possibilitando a implantação dos empreendimentos" [...] "além da intervenção direta no espaço, igualmente importante foi o esforço realizado pelo Estado para criar um cenário favorável ao desenvolvimento da região" (RYFF, 2002 p. 60).

Criado em 3 de abril de 1978 pela Lei Municipal no 61, Decreto Municipal no 14.203, de 18/09/1995, Art. $1^{0}$ - que transformou o Parque Zoobotânico de Marapendi em Parque Municipal Ecológico de Marapendi e acresceu a sua área atual o conjunto formado pelas áreas doadas ao Município, num total de 1.203.712,60m2.

A região é de propriedade particular, os lotes da APA de Marapendi situados de frente para a Praia da Reserva seriam transformados num grande parque público à beira-mar. Em troca, outro trecho (58 mil metros quadrados) às margens da Avenida das Américas que são considerados intocáveis por estarem em Zona de Conservação da Vida Silvestre (ZCVS) para protegerem a fauna e flora da região, seria liberado para o campo de golfe de dimensões olímpicas.

Apesar da ZCVS ser apenas 6\% do total do campo de golfe, a proposta está gerando grande polêmica entre a comunidade civil, científica e ambientalistas, por falta de estudos prévios. O campo de golfe se 
estenderá por uma área de um milhão de metros quadrados, também na APA de Marapendi, às margens da Avenida das Américas. Ryff (2002, p. 31) explica que:

[...] não é raro encontrar construções em todos os "domínios geomorfológicos" da Baixada de Jacarepaguá, onde coexistem variados tipos de ocupações que têm uma mesma origem quanto ao histórico de propriedade da terra quando se trata de "loteamentos regulares". Mas com o crescimento da região, após os novos lançamentos imobiliários no período mais recente de expansão, o cenário evoluiu para um arranjo mais complexo com o aparecimento em grande quantidade das formas de ocupação ilegais.

A decisão da prefeitura de não preservar o terreno contraria a Lei Federal 11.428/2006. A APA de Marapendi tem dois ecossistemas, o mangue e a restinga, que pertencem à Mata Atlântica e a lei 11.428/2006 classifica a Mata Atlântica como patrimônio nacional e ainda tem espécies de animais e plantas ameaçados de extinção.

A figura abaixo (Figura 3) mostra a área da APA de Marapendi margeando o litoral da Barra da Tijuca em sua atual formatação.

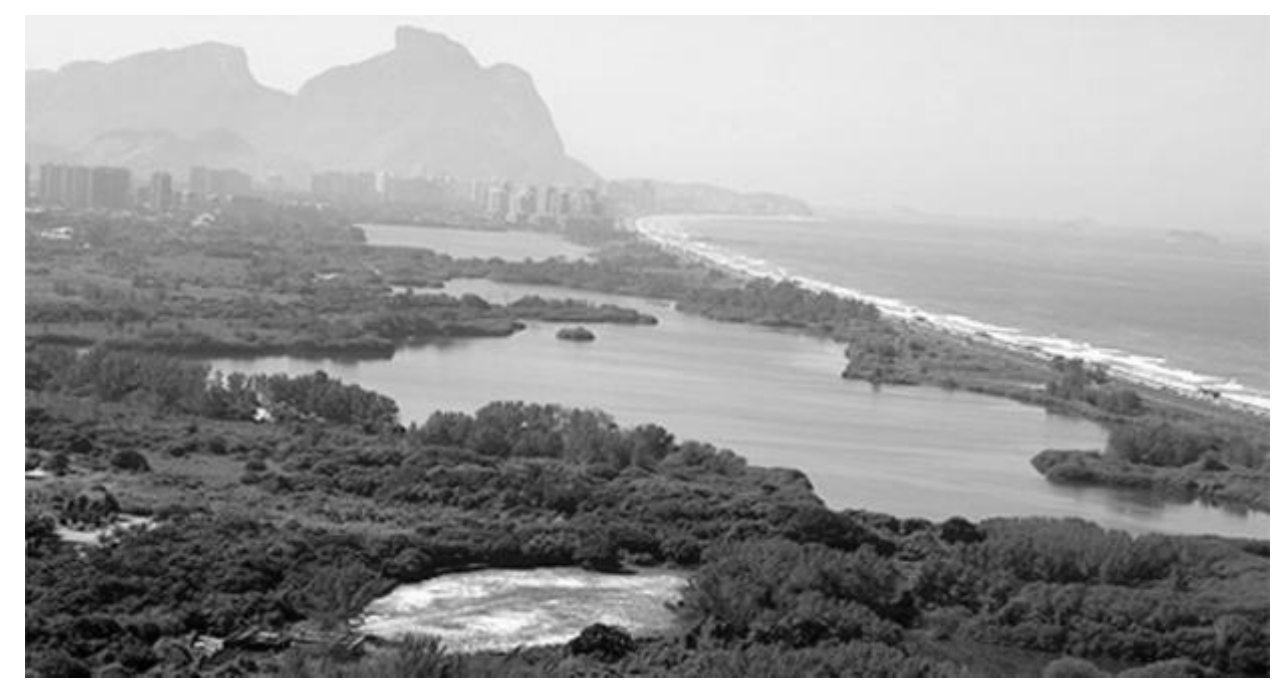

Figura 3. Área construída do COMPERJ

Fonte: Disponível em: http://www.comperj.com.br/Apresentacao.aspx Acesso em: 11 set. 2013.

A luta pela criação da Área de Proteção Ambiental (APA) de Marapendi se remete aos idos de 1990. O vereador Alfredo Sirkis, eleito em 1988, apresentou um projeto de Lei criando a APA Marapendi com objetivo principal de preservar a restinga junto à praia, e algumas áreas de vegetação de 
restinga, remanescentes, do outro lado da lagoa. Comparada com as lagoas da Tijuca, Camorim e de Jacarepaguá, a de Marapendi era a menos poluída.

O estudo de Ryff (2002) comenta sobre a ocupação das áreas naturais da Barra da Tijuca nas décadas finais do século XX mostrando toda a estrutura legal montada para qualquer tipo de uso e apropriação do território. Observa que no Título IV, da Lei de uso e ocupação do solo, mais uma vez é reforçado o atendimento à função social da propriedade, "com a subordinação do uso e ocupação do solo ao interesse coletivo" e à proteção do meio ambiente (p. 74).

No Capítulo IV, sobre áreas sujeitas a intervenção, o Art. 60 determina que "estarão sujeitas a proteção ambiental as áreas que necessitem de proteção legal e de manutenção, recuperação ou revitalização nas condições do meio ambiente natural ou construído" [...] e o parágrafo único especifica que "as áreas sujeitas à proteção ambiental serão gradual e progressivamente declaradas Áreas de Especial Interesse Ambiental, para a execução de projetos específicos” (RYFF, 2002, p. 75).

Observa-se em todos os artigos e seções que existe uma preocupação específica com o tipo de composição natural (vegetal, animal e mineral) da região protegida o que, por si só, já emprega grande importância ao texto. Porém, em outras circunstancias, ele é apropriado com objetivo do bem coletivo e da melhoria das condições de vida para a população do bairro.

O crescimento urbano de uma grande cidade como o município Rio de Janeiro vem ocorrendo num contexto onde diferentes agentes do capital competem para atingirem os seus objetivos financeiros (ACSERALD, 2002; CARNEIRO, 2005; RYFF, 2002; SOUZA, 2000; ZHOURI, 2005), o que de fato não difere muito das outras metrópoles mundiais do sistema capitalista [...] "mas cabe ao Estado como participante e mediador desse processo de urbanização, envolvendo diversos interesses, maior comprometimento social na produção espacial da cidade" (RYFF, 2002 p. 86).

A participação nos conflitos ambientais de agentes que não pertencem ao Estado e nem se constituem como empreendimentos capitalistas. "Interessa-nos estimar a importância da participação de agentes desse tipo na emergência e desenvolvimento dos conflitos, a natureza sociológica e o papel das entidades e as implicações e conexões entre os conflitos descritos e a operação de estruturas sociopolíticas mais gerais". (CARNEIRO 2005 , p. 35). 
Ryff (2002) confirma ainda que, nesse sentido, o modo como a questão ambiental passa a ser vista e compreendida na sociedade capitalista afeta diretamente o processo de organização espacial dessas metrópoles. Afeta o equilíbrio social e as tentativas de se estabelecer a justiça a quem de direito.

A metropolização, entendida como o fenômeno da complexificação e do crescimento das funções e das dimensões espaciais de cidades centrais (SANTOS, 1992; CORRÊA, 1992, 1996, 1997) principalmente nos países emergentes, tornou-se, entre outras coisas, sinônimo de degradação ambiental. E no caso do Rio de Janeiro não foi diferente. "A expansão dos limites da cidade e o seu crescimento implicaram numa série de impactos negativos ao meio ambiente, com graves consequências para os seus habitantes" (RYFF, 2002 p. 87).

\section{Considerações Finais}

A reconstituição dos momentos históricos em que a região metropolitana do Rio de Janeiro sofreu acréscimo de população e infraestrutura e toda conjuntura de fenômenos sociais e ambientais que acometeram seus cidadãos, mostrou que o conjunto das políticas públicas estabelecidas para estruturar o crescimento urbano fomentado para as cidades e estabelecendo as diretrizes gerais da política urbana, promoção da saúde ambiental e de justiça socioambiental não foram suficientes para frear o ímpeto desenvolvimentista e interesses diversos no município.

Irregularidades e distorções de todos os tipos e formas foram empregadas para assegurar a utilização dos espaços naturais preservados da região, causando uma gama de discussões e conflitos no interior da sociedade fluminense.

Percebe-se que, enquanto o poder (econômico e político) e os interesses individuais forem mais importantes que as necessidades públicas e a preservação da natureza, as Leis não passam de meras formalizações e garantia de impunidade e desrespeito. 


\section{REFERÊNCIAS}

ABREU, M. A. A evolução urbana do Rio de Janeiro. 3. ed. Rio de Janeiro: IPLAN, 1997.

ACSELRAD, Henri (org). Conflitos Ambientais no Brasil. Rio de Janeiro: Relume Dumará, 2004

ACSELRAD. H.; MELLO. C. C. A. Conflito social e risco ambiental: o caso de um vazamento de óleo na Baía de Guanabara. In: ALIMONDA. II. (Org.). Ecologia Política - Naturaleza Sociedad y Utopia. Buenos Aires: CLACSO. 2002. P. 293-317.

ALÉM, Ana Cláudia et al.. O BNDES em um Brasil em transição. Rio de Janeiro : BNDES, 2010. 460 p.

BRASIL. Constituição Federal de 1988. Disponível em: www.planalto.gov.br. Acesso em: 09 abr. 2014. . CONAMA. Resolução Conama no 237, de 19 de dezembro de 1997. Brasília, 1997.

CAETANO, P. F. COMPERJ e arco metropolitano no Rio de Janeiro: Grandes Projetos Logísticos como Vetores de Políticas Públicas no Território Fluminense. Pesquisa desenvolvida no âmbito do grupo de pesquisa GeTERJ (Gestão Territorial no Rio de Janeiro). Rio de Janeiro, 2008.

CASTRO, Antonio O. et al. Impactos sociais da atividade de exploração e produção de petróleo na baixadas litorâneas e norte fluminense. Rio de Janeiro: INT, 2003. 48 p. (Nota Técnica, 13).

CARRIL, L. O moderno e o descolamento da natureza. (Texto elaborado para relatório de Qualificação de Doutorado novembro de 2002).

CAVALCANTI, R. N. A efetividade dos instrumentos jurídicos para a proteção ambiental: o caso do licenciamento, 2010. $155 \mathrm{f}$.

CHESNASI, F.; SERFATI, C. Ecologia e condições físicas da reprodução social: alguns fios condutores marxistas. Revista Crítica Marxista, São Paulo, n.16, Boitempo Editorial, 2003.

CORRÊAA, R. L. Os Centros de Gestão do Território: Uma nota. Revista Território, Rio de Janeiro, v. 1, p. 23-30, 1996.

. Corporação, Práticas Espaciais e Gestão do Território. Revista Brasileira de Geografia, Rio de Janeiro, v. 54, n. 3, p. 115-122, jul/set, 1992.

.Interações espaciais. In: CASTRO, I.E.; GOMES, P. C. C; CORRÊA, R. L. (org.). Geografia: conceitos e temas. Rio de Janeiro: Bertrand Brasil, 1997.

Expansão do espaço urbano no Rio de Janeiro. In: BERNARDES, Lysia Maria Cavalcanti; SOARES, Maria Therezinha de Segadas. Rio de Janeiro: cidade e região. Rio de Janeiro: Prefeitura da Cidade do Rio de Janeiro, (1961) 1987.

DÓREA, L. S. S. A PNMA e os avancos na política e legislação ambiental no Brasil, Resenha crítica. Núcleo Interdisciplinar de Pesquisa e Extenso em Direito Ambiental e Direito Animal - NIPEDA. Disponível em: < http://www.nipeda.direito.ufba.br/pt-br/node/90. Acesso em: 10 jun. 2014.

FAUSTINO, Cristiane e FURTADO, Fabrina. Indústria do petróleo e conflitos ambientais na Baía de Guanabara: o caso do Comperj. Relatório da Missão de Investigação e Incidência Plataforma Dhesca - Relatoria do Direito Humano ao Meio Ambiente, Rio de Janeiro, $1^{\text {a }}$ Edição, 2013. 
FOLADORI, G. Limites do desenvolvimento sustentável. Tradução: Marise Manoel. Campinas, SP: Ed. da UNICAMP, 2001.

FRANCA, Luciano Marcelo; MANTOVANELI JUNIOR, Oklinger and SAMPAIO, Carlos Alberto C.. Governança para a territorialidade e sustentabilidade: a construção do senso de regionalidade. Saude soc. [online]. 2012, vol.21, suppl.3, pp. 111-127.

HAESBAERT, R. O mito da desterritorialização: o fim dos territórios a multiterritorialidade. 2. ed. Rio de Janeiro: Bertrand Brasil, 2006.

LAYRARGUES, P. P. Educação para a gestão ambiental: a cidadania no enfrentamento político dos conflitos socioambientais. In: LOUREIRO, C. F. B.; LAYRARGUES, P. P.; CASTRO, R. S. (Org). Sociedade e meio ambiente: a educação ambiental em debate. 3. ed. São Paulo: Cortez, 2002. p. 87-155.

LEFF, E. Epistemologia ambiental. São Paulo: Cortez, 2011.

LOUREIRO, C. F. B. Educação ambiental e gestão participativa na explicitação e resolução de conflitos. Gestão em Ação, Salvador, v. 7, n. 1, p. 37-50, jan./abr. 2004.

POUlAnTZAS, N. O estado, o poder, o socialismo. Tradução de Rita Lima. Rio de Janeiro: Graal, 1981.

PIMENTEL, Carolina. Governo do Rio vai recorrer de suspensão de licenças ambientais do Comperj. EBC. Disponível em: http://ebc.com.br/noticias/brasil/2013/05/governo-do-rio-vai-recorrer-de-suspensao-de-licencas-ambientais-do-comperj. Acesso em: 03 abr. 2014.

RANDOLPH, R.; BESSA, E. O meio ambiente como forma especifica de organização territorial: elementos para uma discussão conceitual. Cadernos IPPUR/UFRJ, Rio de Janeiro, v. 7, n.1, p. 73-84, abr. 1993.

RIBEIRO, L. C. Q. Dos cortiços aos condomínios fechados: as formas de produção da moradia na cidade do Rio de Janeiro. Rio de Janeiro: Civilização Brasileira, 1997.

RYFF, C. E. M. Expansão urbana e conflito ambiental: o caso Downtown. Dissertação (Mestrado em Planejamento Urbano e Regional) - Universidade Federal do Rio de Janeiro, IPPUR, 2002.

VELHO, G. A utopia urbana: um estudo de antropologia social. 5. ed. Rio de Janeiro: Zahar, 1989.

SACHS, W. Whose environment? In: . On the archaeology of the development idea: six essays. Pennsylvania:

Pennsylvania State University, nov. 1989

SANTOS, M. A redescoberta da natureza. Estud. Av. [online]. 1992, vol.6, n.14, pp. 95-106

Técnica espaço tempo: globalização e meio técnico-científico informacional. São Paulo: Hucitec, 1994.

SOUZA, M. L. O desafio metropolitano: um estudo sobre a problemática sócio- espacial nas metrópoles brasileiras. Rio de Janeiro: Bertrand Brasil, 2000.

ZHOURI, A. et al. A insustentável leveza da política ambiental: desenvolvimento e conflitos socioambientais. Belo Horizonte: Autêntica, 2005. 